\title{
Assessment of Current and Future Domestic Water Allocation for Mandalay City
}

\author{
${ }^{1}$ Kaung Myat, and ${ }^{2}$ Nilar Aye
}

\begin{abstract}
This study investigates the current water demand and supply situation in Mandalay city in 2014 and evaluates the changes of water demand and supply due to completion of future project scenarios for 2015 to 2030. The Water Evaluation and Planning (WEAP) model was used to assess present and future domestic water allocation for Mandalay city till 2030. The current water demand and supply for domestic need was firstly analyzed. In Mandalay city, the water supplied to demand site was mostly contributed by groundwater and a little demand was met by Sedawgyi dam and Ayeyarwaddy river. Required data was collected from Mandalay City Development Committee (MCDC) and Irrigation Department. The collected data was given as input to the WEAP model and the model generated water demand, supply delivered and unmet demand of reference scenario based on current account year. The model results revealed that two townships were met with the required demand and three townships were facing water shortage all year round. So, new water resources may be vitally needed to balance the unmet demand. According to proposed plan from MCDC, two new infrastructure completion of Ayeyarwaddy river and Dotehtawaddy river pumping projects were considered for future scenarios to reduce the unmet demand.
\end{abstract}

Keywords-future project scenarios, Water Evaluation and Planning (WEAP) Model, domestic water allocation, reference scenario, unmet demand

\section{INTRODUCTION}

Water allocation is the process of sharing limited natural resources between different regions and competing users. In simple term, it is the mechanism for determining who can take water, how much they can take, from which location and for what purposes. As water scarcity has increased globally, water allocation plans and agreements have taken on increasing significance in resolving international, regional and local conflicts over access to water. While objectives and approaches have been evolved over time, water resources allocation has fundamentally remained the process of determining how much water is available for human use and how that water should be shared between competing users.

Today, water shortage is one the real challenges facing many countries in the world. In Myanmar, the process of population growth, urbanization and industrialization are occurring at an ever increasing phase at every year. These processes result in increased demand for water use in the

Kaung Myat, Mandalay Technological University, Republic of the Union of Myanmar, kaungmyat.mtu.civil@gmail.com

Nilar Aye, Mandalay Technological University, Republic of the Union of Myanmar, dnilaraye@gmail.com sector of domestic water supply, industry, agriculture and hydropower generation. Thus, the water allocation criteria and water resources development projects are undertaken to address this requirements. According to report from Asian Development Bank, total water withdraw from available water resources in Myanmar are around $89 \%$ for agriculture, $10 \%$ is for municipalities and $1 \%$ is for industries. Approximately $91 \%$ of the total water withdraw comes from surface water and 9\% from groundwater. Groundwater is mostly used for domestic purpose.

As the difference between water resources and demand is ever increasing, the government is facing with the increasingly difficult task of allocating the available water resources among the competing demands. In the face of growing competition, the water allocation has evolved to be a complex process. Simulation and optimization modeling techniques can help to analyze this complex process and develop sustainable water allocation solutions. Over the years, a number of computerbased tools that employ simulation and optimization techniques have been developed. Among them, Water Evaluation and Planning Model (WEAP) developed by Stockholm Environment Institute, has been used worldwide in order to perform allocation, scenario analyses and reporting data tool for water resources management.

\section{BACKGROUND STUDY AREA}

Mandalay city is located in the central region of Myanmar at $21^{\circ} 58^{\prime} \mathrm{N} 96^{\circ} 04^{\prime} \mathrm{E}$. It is also the second largest city and the last royal capital of Myanmar. It is located 445 miles north of Yangon and bordered by the Ayeyarwaddy river at the west. The city has an estimated population of 1.21 million and is the capital of Mandalay Region. Mandalay is the main commercial, educational, health and economic hub of Upper Myanmar and considered as the centre of Buddhism in Myanmar. Mandalay city downtown area consists of five townships as shown in Fig 1.

In Mandalay city municipal area, water is supplied by a network of piped water supply system from tube wells, river pumping and reservoirs. Presently, piped water supply is being provided to Aung Myae Tharsan, Chan Aye Tharsan, Maha Aung Myae, Chan Mya Tharzi and a small part of Pyi Gyi Tagon township. As a whole, overall population accessed to piped water supply in Mandalay city is $72.9 \%$ of total city population. Piped water supply system is available only during particular times of the day in the different townships and intermittently supply in almost zone. In general, citywide infrastructure networks and municipal services do not reach at 
adequate level for a large proportion of the urban population. Consumers have adapted to inadequate provision by improvising self-supply, usually involving private tube wells. During the hot season, residence face with water shortage because pumping stations are unable to operate. Area that are far from pumping stations face difficulties all year round.



Fig. 1 Map of Mandalay City

\section{WEAP SYSTEM MODELLING}

The WEAP model is an integrated water resources management tools to enable evaluation of planning and management issues associated with water resources development. The WEAP model can be applied to both municipal and agricultural system allocation and can address a wide range of issues including sectoral demand analyses, water allocation priorities, streamflow simulation, reservoir operation, ecosystem requirements and project cost-benefit analyses.

To allow simulation of water allocation, the elements that comprise the water demand-supply system and their spatial relationship are characterized. The system is represented in terms of its various water sources (e.g., surface water, ground water, desalinization and water reuse elements), withdrawl, transmission, reservoir, and wastewater treatment facilities, and water demands (i.e., user-defined sectors typically comprising of domestic, industry, mines, irrigation supply, etc). The data structure and level of detail can be customized according to the requirement of analysis and limited data.

Firstly, time step boundary is set up. Year 2014 is used as current account year which is the basic definition of the water supply as it currently exist including specifications of supply and demand data for the first year of study on a monthly basic. Last year of scenario is 2030 and time steps per year is 12 based on calendar month. The study period may start from January, 2014 and end at December, 2030. The WEAP model for Mandalay city was then constructed which operates on the basic principle of water balance for every node and link in the system subject to demand priorities and supply preferences. Fig. 2 shows WEAP model for Mandalay city which consist of 16 demand nodes by the red circles, 9 groundwater nodes by the green squares and 1 reservoir node by green triangle. Demand site nodes were connected with the water resources nodes by green line transmission links by demand priority and supply preference order.

The various parameters which were fed to WEAP model were annual activity level, annual water use rate, monthly variation and consumption for demand nodes, storage capacity, initial storage, maximum withdrawal and natural recharge for groundwater nodes and physical and operation data for reservoir nodes, etc. All the data was compiled and brought in the format acceptable to model. The model simulation for reference and future scenarios were run for 16 years.

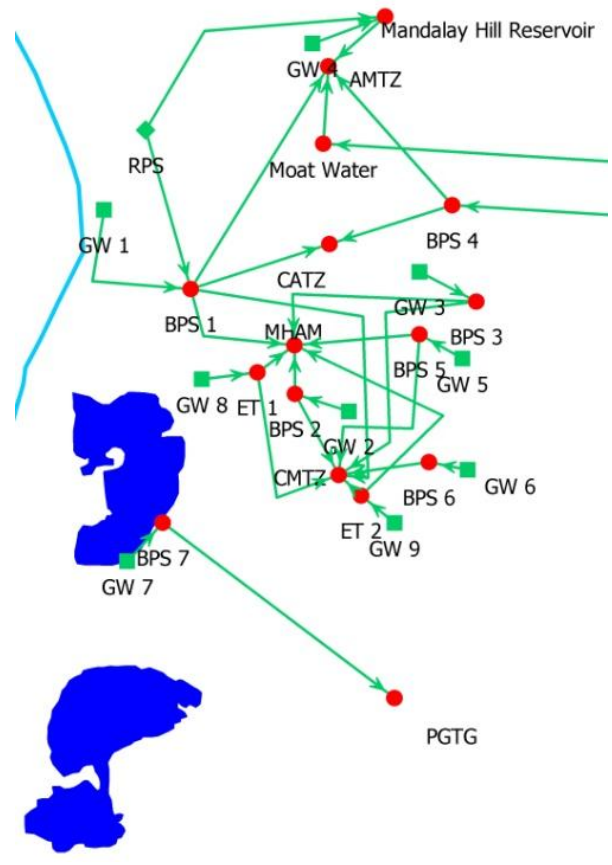

Fig. 2 WEAP Model for Mandalay City

\section{RESUlts AND Discussion}

Four main scenarios were considered in the assessment. Scenario 1 was reference scenario. Scenario 2 was the changes of water supply and demand situation if population will grow with Average Annual Growth Rate. Scenario 2 was after completion of Ayeyarwaddy river pumping project and Scenario 3 was after completion of Ayeyarwaddy river and Dotehtawaddy river pumping project.

\section{A. Scenario 1 (Reference Scenario)}

This scenario represents the current system condition with water supplies and demand sites for five townships in Mandalay city. It is based on Year 2014 condition for which the current account data are established. Fig. 3, Fig. 4, Fig. 5 and Fig. 6 shows the water demand, supply delivered, unmet demand and demand sites coverage of five townships in Mandalay city for scenario 1. According to model result, two townships, Aung Myae Tharsan and Chan Aye Tharsan townships were fully met with the required demand. Other 
remaining three townships, Chan Mya Tharzi, Maha Aung Myae and Pyi Gyi Tagon townships were facing water shortage all year round. Among these three townships, Pyi Gyi Tagon township has the highest unmet demand.

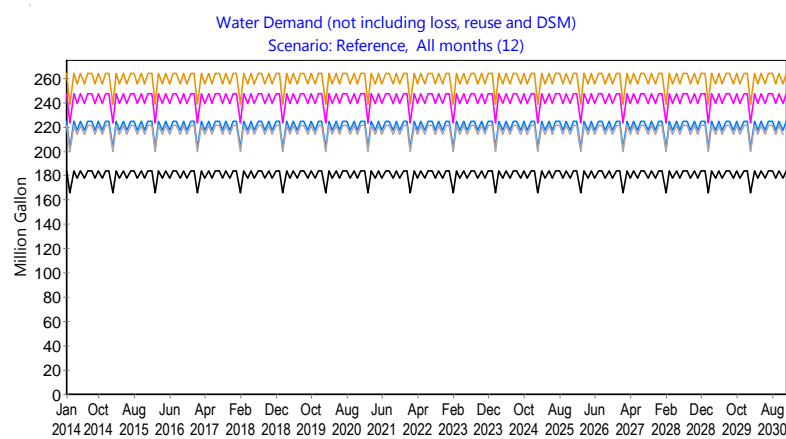

Fig. 3 Water Demand for Mandalay City (Scenario 1)

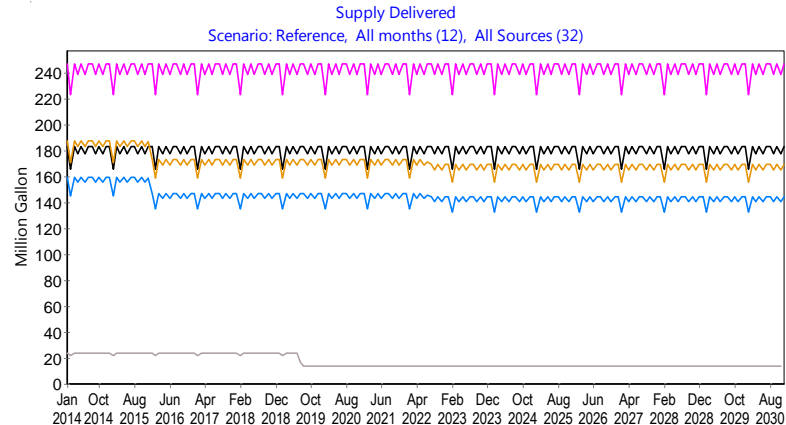

Fig. 4 Supply Delivered to Mandalay City (Scenario 1)

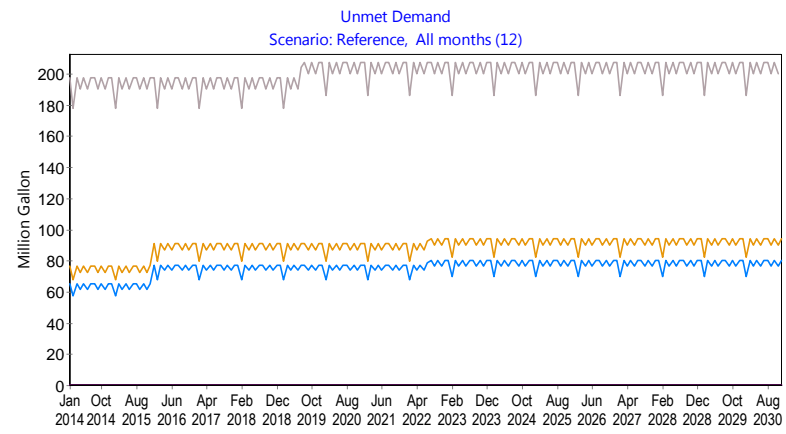

Fig. 5 Unmet Demand of Mandalay City (Scenario 1)

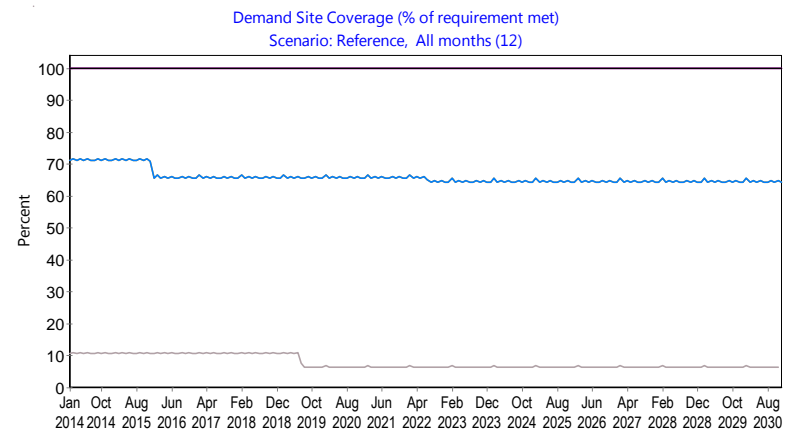

- AMTZ

- CATZ

- CMTZ

- MHAM

Fig. 6 Demand Site Coverage of Mandalay City (Scenario 1)

\section{B. Scenario 2 (If population will grow with Average Annual Growth Rate)}

Since population growth is the main threatening reason for the water crisis, water planner need to analyse how population growth will affect on water supply and demand situation. This scenario represent the impact of increasing population with average annual growth rate.

According to the report of Urban Planning Departement of Mandalay City Development Committee, average annual growth rate (AAGR) for Mandalay City may be $1.68 \%$ during 2014 to 2030. If population of Mandalay City will grow with AAGR with no additional supply, the monthly unmet demand will be 135.34 MG for Chan Mya Tharzi township, 111.05 MG for Mahar Aung Myae township and 236.92 MG for Pyi Gyi Tagon township at 2030. But two twonships of Aung Myae Tharsan and Chan Aye Tharsan were met with required demand and had no unmet demand even if population will grow with average annual growth rate untill 2030. Fig. 7, Fig. 8, Fig. 9 and Fig. 10 show water demand, supplied delivered, unmet demand and demand site coverage of five townships in Mandalay city for scenario 2 .

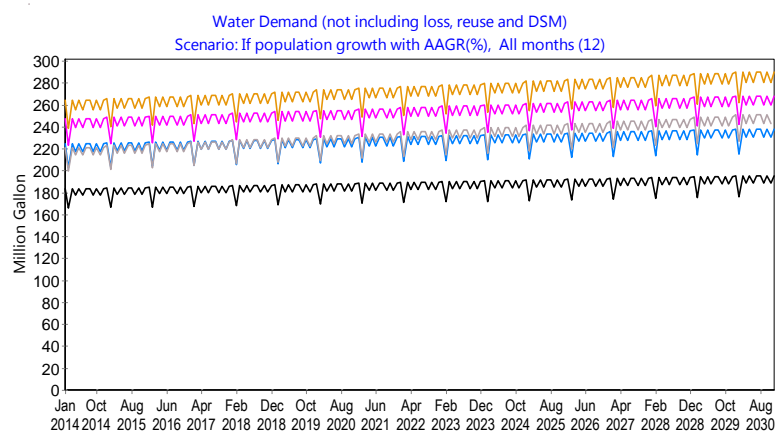

Fig. 7 Water Demand of Mandalay City (Scenario 2)

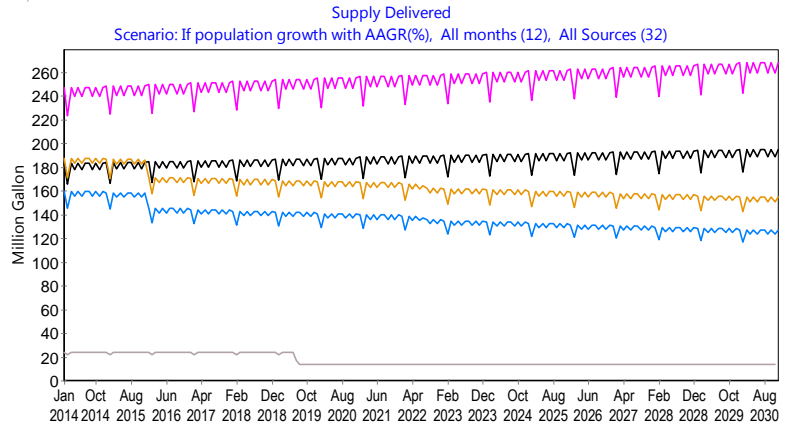

Fig. 8 Supply Delivered to Mandalay City (Scenario 2)



Fig. 9 Unmet Demand of Mandalay City (Scenario 2) 


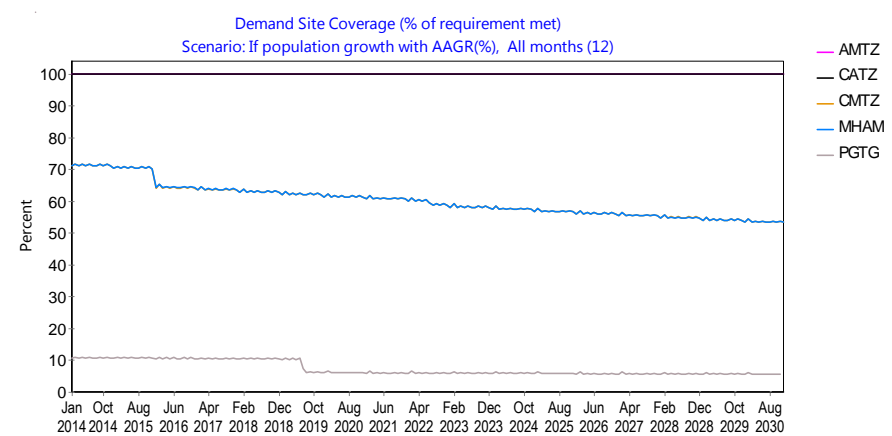

Fig. 10 Demand Site Coverage of Mandalay City (Scenario 2)

\section{Scenario 3 (After completion of Ayeyarwaddy River pumping project)}

According to MCDC master plan, it is mentioned that new Ayeyarwaddy river pumping project will be completed at 2020. This project can be supplied 10 MGD for Mandalay city. This scenario reveals the condition of water supply and demand situation due to combination of scenario 2 and the completion of this project.

The model results revealed that Chan Mya Tharzi and Mahar Aung Myae townships were met with reqiured demand from project completion year of 2020 to 2027 but there will be a little unmet demand from the start of year 2028 to until 2030 because of population growth. Fig. 11, Fig. 12 and Fig. 13 show supply delivered, unmet demand and demand site coverage of five townships in Mandalay city for scenario 3.
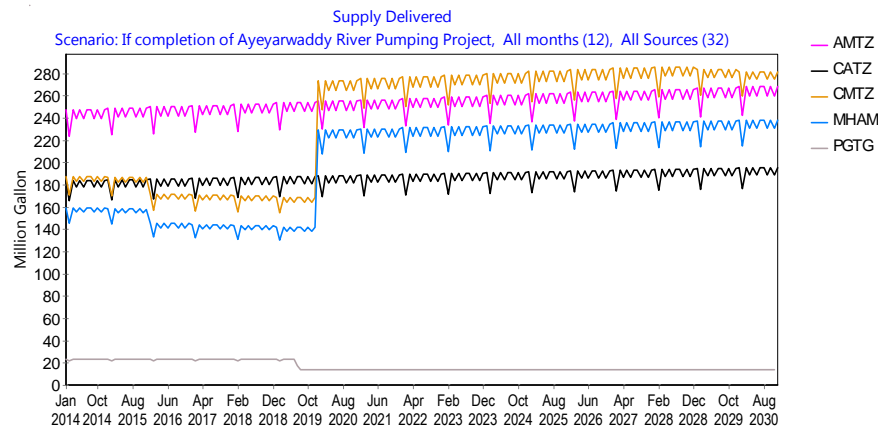

Fig. 11 Supply Delivered to Mandalay city (Scenario 3)
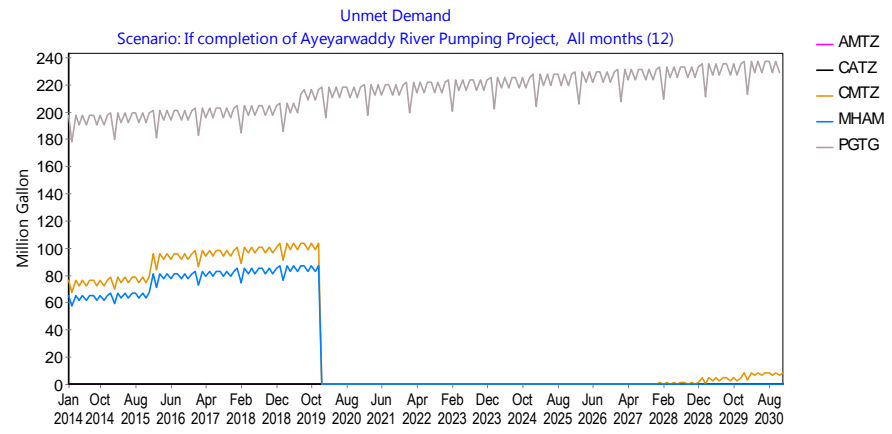

Fig. 12 Unmet demand of Mandalay city (Scenario 3)

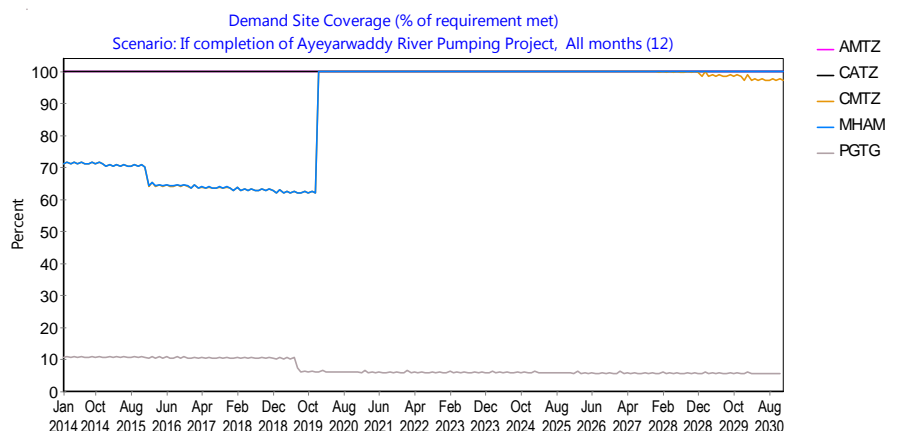

Fig. 13 Demand Site Coverage of Mandalay City (Scenario 3)

D. Scenario 4 (After completion of Ayeyarwady River and Dotehtawaddy River pumping project)

From MCDC proposed plan, it is reported that Dotehtawaddy river pumping project will be completed at Year 2025 and 3 MGD can be supplied to Pyi Gyi Tagon township. This scenario represent the combination of scenario 2, 3 and completed condition of new Dotehtawaddy River pumping project. The result generated by model showed that the monthly unmet demand of Pyi Gyi Tagon township will decline from 225.36 MG to $134.26 \mathrm{MG}$ at project completed Year 2025. But there may be fluctuation of unmet demand and increase to $143.93 \mathrm{MG}$ per month at the end of Year 2030. Fig. 14, Fig. 15 and Fig. 16 show supply delivered, unmet demand and demand site coverage of five townships in Mandalay city for scenario 4.

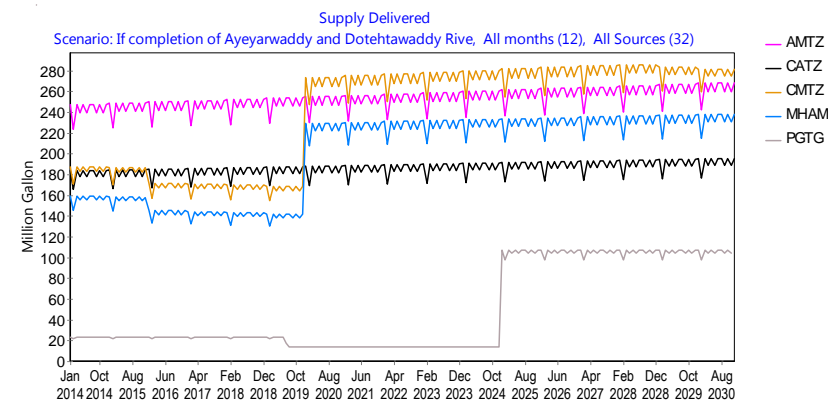

Fig. 14 Supply Delivered to Mandalay City (Scenario 4)

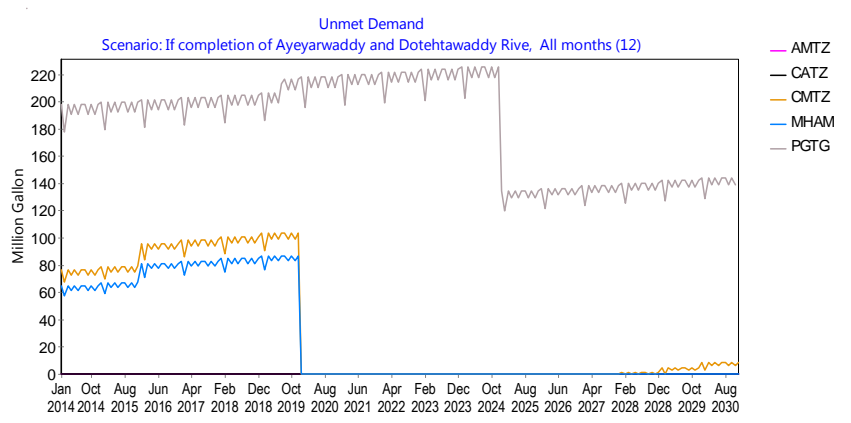

Fig. 15 Unmet Demand of Mandalay City (Scenario 4) 


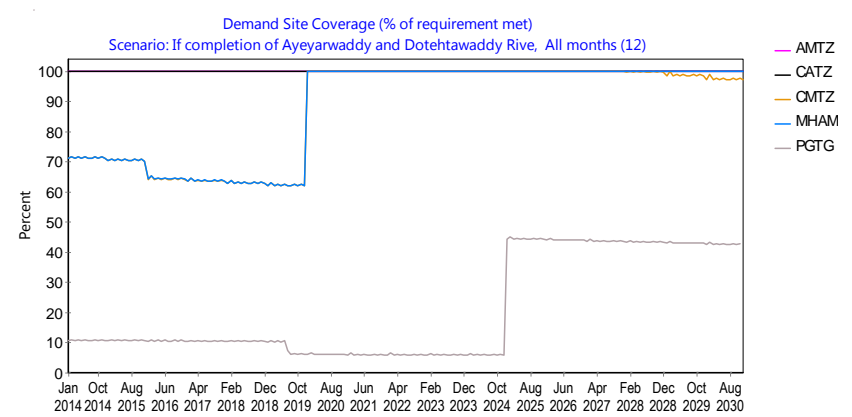

Fig. 16 Demand Site Coverage of Mandalay City (Scenario 4)

\section{CONCLUSION}

This study was undertaken to investigate the water allocaiton of Mandalay city for current and future with Water Evaluation and Planning (WEAP) model in terms of water demand, supply delivered, unmet demand and demand site coverage at city level. The assessment of water supply and demand using WEAP is conducted based on the reference data of Year 2014. The assessment model was based on four scenarios. For reference scenario, overall unmet demand was $381.52 \mathrm{MG} / \mathrm{month}$ and demand site coverage was $70.5 \%$ at 2030 for Mandalay city. For Scenario 2, overall unmet demand will rise to $483.31 \mathrm{MG} /$ month and demand site coverage will be decreased to $62.38 \%$ at 2030 because of no additional supply with population growth. Under Scenario 3, demand site coverage for Chan Mya Tharzi and Mahar Aung Myae townships were $100 \%$ till Year 2027 and $98.5 \%$ between Year 2028 and 2030. But, Pyi Gyi Tagon Township will be $10.61 \%$. And overall unmet demand will be decreased to 245.46 MG/month and overall demand site coverage for Mandalay city will be increased to $80.6 \%$. After the Scenario 4, the unmet demand of Year 2025 for Pyi Gyi Tagon township will decline to half of Year 2024 demand and overall demand site coverage for Mandalay city was about $88 \%$. If about $153 \mathrm{MG} / \mathrm{month}$ of new projects can be created, Mandalay city will have no unmet demand at Year 2030.

To conclude above, these two projects will be vitally needed and new additional projects should be planned to balance the unmet demand for Mandalay city according to future scenarios and WEAP model is a very useful water management tool to predict water shortage and changes in consumption for current and future.

\section{ACKNOWLEDGMENT}

Firstly, the author is greatly indebted to Dr. Nilar Aye, Professor and head of Department of Civil Engineering, Mandalay Technological University for her true-line guidance, precious supervision and editing to complete this paper. The author also wishes to acknowledge to Daw Aye Aye Thant, Lecturer of Department of Civil Engineering, Mandalay Technological University, for her support, careful guidance, and great interest. The author would like to express his sincerest gratitude to $\mathrm{U}$ Zaw Win Aung, Sub Assistant Engineer of Water Supply and Sanitation Department, Yangon City Development Committee, for his kind help, and great suggestion in enabling to run the WEAP model. Moreover, I would like to grate thankful to Stockholm Environment
Institute for providing free license of WEAP software to do this paper. Special thanks to all officers and staffs from Mandalay City Development Committee and Irrigation Department for providing the required data, useful reference books and constant contribution to invaluable knowledge. Finally, the author greatly expresses his thanks to all persons who concerned to support for completion of this paper.

\section{REFERENCES}

[1] Hla Myo, "Mandalay City Development Committee report," Mandalay, Myanmar, 2014.

[2] Asian Development Bank, "Preparing Mandalay Urban Services Improvement Project report, " Issue A, 2014.

[3] Asian Development Bank, "Urban Development and Water Sector Assessment, Strategy, and Road Map for Myanamr, " 2013.

[4] Robert Speed, Li Yuanyuan, Tom Le Quesne, Guy Pegram and Zhou Zhiwei, "Basin Water Allocation Planning," 2013.

[5] Stockholm Environment Institute, "WEAP: Water Evaluation and Planning System - User Guide, Boston, USA, ” 2011.

[6] Stockholm Environment Institute, "WEAP: Water Evaluation and Planning System - Tutorial, Boston, USA, ” 2011

[7] http://www.weap21.org

About Author (s):

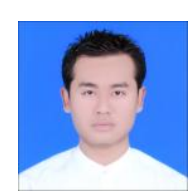

Mr. Kaung Myat, Ph.D Student, Department of Civil Engineering, Mandalay Technological University, Republic of the Union of Myanmar, Specialized field is Water Resources Engineering.

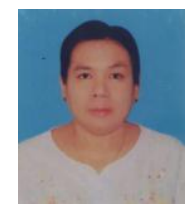

Dr. Nilar Aye, B.E. (Civil), RIT; M.Civ.(Engg:); University of Hannover, GERMANY; Ph.D.(CWRE), YTU, Professor and Head, Department of Civil Engineering, Mandalay Technological University, Republic of the Union of Myanmar, Specialized field is Water Resources Engineering and Watershed Management. 